\title{
Correlates of fruit and vegetable intake among Norwegian schoolchildren: parental and self-reports
}

\author{
Elling Bere* and Knut-Inge Klepp \\ Institute for Nutrition Research, University of Oslo, Box 1046 Blindern, 0316 Oslo, Norway
}

Submitted 5 January 2004: Accepted 11 March 2004

\begin{abstract}
Objectives: To identify correlates of 6th and 7th graders' (age 10-12 years) fruit and vegetable intake, to investigate parent-child correlations of fruit and vegetable intake, and to compare parents' and children's reports of children's accessibility, skills and preferences with respect to fruit and vegetables.

Design: The results presented are based on the baseline survey of the "Fruits and Vegetables Make the Marks Project', where 38 schools participated.

Setting: Fruit and vegetable intake was measured by food frequency questions. Theoretical factors, based on Social Cognitive Theory, potentially correlated to intake were measured, including behavioural skills, accessibility, modelling, intention, preferences, self-efficacy and awareness of 5-a-day recommendations.

Subjects: In total, 1950 (participation rate 85\%) 6th and 7th graders and 1647 of their parents participated.

Results: Overall, $34 \%$ of the variance in the pupils' reported fruit and vegetable intake was explained by the measured factors. The strongest correlates to fruit and vegetable intake were preferences and accessibility. The correlation between the children's and their parents' fruit and vegetable intake was 0.23. The parents perceived their children's accessibility to be better than what was reported by the children $(P<0.01)$, while the children reported their skills to be better than what was perceived by their parents $(P<0.01)$.

Conclusion: The results from this study clearly point to a need for nutrition interventions aimed at parents. An important next step will be to investigate whether the identified correlates predict future fruit and vegetable intake, and whether they mediate any changes in intake in an intervention study.
\end{abstract}

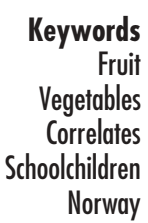

Epidemiological evidence for the health benefits of eating fruit and vegetables is convincing ${ }^{1}$. In Norway, the average intake of fruit and vegetables among adults is only about half the recommended amount ${ }^{2,3}$. This also holds true for children and adolescents ${ }^{2,4}$. To increase fruit and vegetable intake, knowing what factors determine intake in specific target groups is essential ${ }^{5}$.

Correlates of fruit and vegetable intake among children and adolescents have been studied in a number of settings, and statistically significant relationships have been found between fruit and vegetable intake and factors such as knowledge levels ${ }^{6,7}$, outcome expectations ${ }^{6,8-10}$, preferences $^{6,10-14}$, self-efficacy $6,9,10,12,15$, family and peer influences $^{6,14,16-18}$, availability and/or accessibility ${ }^{6,9,19-22}$, as well as demographic factors including gender, age and socio-economic status ${ }^{16}$. The reported strengths of these relationships are, however, rather low. Most reported bivariate correlation coefficients between a determinant and adolescent fruit and vegetable intake are moderate to weak (0.1-0.2), and none above 0.4 have been reported.
Furthermore, only a few analytical studies investigating correlates of fruit and vegetable intake among European children and adolescents have been conducted $^{7,18,23,24}$.

Social Cognitive Theory (SCT) can serve as a useful theoretical framework when investigating factors associated with fruit and vegetable intake ${ }^{25,26}$. SCT postulates that behaviour, including dietary behaviour, is the result of environmental factors (such as easily accessible fruit and vegetables or observation of important others performing the behaviour) and personal factors (such as preferences or self-efficacy). SCT also postulates that behaviour can affect environment and cognitions, and that all three factors (behavioural, personal and environmental) affect one another in constant reciprocal relationships ${ }^{26}$.

Parents are important sources of influence on their children's diets ${ }^{11,27}$. They are responsible for the eating environment at home, decide what food to purchase and what to serve, and serve as important role models. Few studies have assessed parent-child correlations in food intake $^{27}$. One study assessing mother-child correlations of 
fruit and vegetable intake showed a strong correlation for fruit intake $(r=0.36)$, but no correlation for vegetable intake $(r=0.00)^{18}$.

When assessing environmental influences of children's fruit and vegetable intake, parents are believed to be able to provide more objective information than their children on factors such as their own intake (modelling) and their children's fruit and vegetable accessibility at home. Parents are also seen as being able to assess their children's behavioural skills and preferences regarding fruits and vegetables. Having children and their parents respond to parallel questions assessing potential determinants for the children's fruit and vegetable intake allows us to compare children's and their parents' reports, and to assess the relative importance of parental intake as correlated to children's eating behaviours. Parent-child comparisons regarding correlates to the children's intake, including children's accessibility, skills and preferences, have not previously been investigated.

The purpose of the present study was to identify environmental and psychosocial correlates of 6th and 7th graders' fruit and vegetable intake, applying SCT and utilising data provided by both pupils and their parents. Furthermore, we investigated the parent-child correlations of fruit and vegetable intake, and compared parents' and children's reports of children's accessibility, skills and preferences with respect to fruit and vegetables.

\section{Methods}

\section{Sample and procedure}

The results presented here are based on the baseline survey of the 'Fruits and Vegetables Make the Marks Project.' The project included 38 schools from Hedmark and Telemark counties in Norway. Small schools with fewer than 10 pupils per grade level were excluded from the sampling frame. Among the remaining primary schools in these two counties, 48 (24 per county) were selected randomly and invited to participate, and 19 schools from each county agreed to participate. All 6th and 7 th graders in these 38 schools were invited to take part in the baseline survey. Informed consent was sought from both parents and the children prior to the study. Ethical approval and research clearance was obtained from The National Committees for Research Ethics in Norway and from The Norwegian Social Science Data Services.

A survey questionnaire was completed by pupils in the classroom, in the presence of a trained project worker. One school lesson ( $45 \mathrm{~min}$ ) was used to complete the questionnaire. A total of 1950 (out of 2287 eligible, 85\%) pupils completed the questionnaire and brought home a parent questionnaire to be completed by one of their parents. Fifty-nine (3\%) children-parents refused to participate, one class (27 children, 1\%) was not able to carry out the survey, and 251 (11\%) children did not attend this specific school lesson and were not re-contacted.
Of the 1950 pupils who completed the questionnaire, 984 were boys and 966 were girls. A total of 1028 pupils were in 6th grade and 922 were in 7 th grade. Age or date of birth was not recorded, but based on available data from similar surveys; the average age of the sample is estimated to be 11.8 years. Overall, 1647 parents ( $84 \%$ of the participating pupils) completed the parent questionnaires; $84 \%$ of these were mothers/female guardians. The average age of the parents was 40.0 years.

\section{Instrument}

Two questionnaires were developed to measure the intake of fruit and vegetables among the children and their parents and to identify correlating factors of the children's intake. Repeated pre-testing, a test-retest study of both questionnaires and a validation study of the children's questionnaire were conducted prior to the baseline survey, indicating that the instruments had acceptable to good reliability. With respect to the potentially correlating factors, Pearson's test-retest correlation coefficients ranged from 0.51 to 0.74 for the children and from 0.78 to 0.84 for the parents ${ }^{28}$. The measure of fruit and vegetable intake had good reproducibility. Spearman's test-retest correlation coefficients between the test and the retest assessments were 0.75 for the children ${ }^{29}$ and 0.80 for the parents (not previously reported). The Spearman's correlation coefficient between the children's fruit and vegetable intake and the validation method (7-day food diaries) was 0.32 , which is similar to results found in other studies $^{29}$.

\section{Pupil questionnaire}

Behavioural factors. Fruit and vegetable Intake was measured by four frequency questions: 'How often do you eat vegetables for dinner?,' 'How often do you eat other vegetables (e.g. carrot for school lunch)?', 'How often do you eat apple, orange, pear or banana?' and 'How often do you eat other fruits or berries?' All four questions had 10 response alternatives ranging from 'never' $=0$ to 'several times a day' $=10$. Fruit and vegetable Behavioural Skills were measured by five statements, including: 'It happens that I cut up fruits or vegetables for myself as a snack'. The five items were measured on a 5-point scale ranging from 'I fully disagree' to 'I fully agree', and were scored from -2 to 2 .

Environmental factors. Accessibility assessed the physical environment, and included five availability and accessibility statements, such as: 'Mother or father sometimes cuts up fruit or vegetables for me as a snack'. The Modelling scale assessed the perceived behaviour of important others (mother, father, friends and siblings, and home economics teacher): e.g. 'My mother eats lots of fruit and vegetables'. The accessibility and modelling items were scaled and scored as the Behavioural Skills items. 
Personal factors. Four personal factors were believed to be related to fruit and vegetable behaviours: intention (to eat 5-a-day), fruit and vegetable preferences, self-efficacy with respect to 5-a-day, and awareness of the Norwegian fruit and vegetable recommendation (5-a-day). Intention was measured by one item: 'I intend to eat at least 5 servings of fruit and vegetables a day'. Preferences were measured by four items, including: 'Fruit and vegetables make my meals taste better'. Self-efficacy was measured by three items, including: 'For me, it would be easy to eat more than 5 servings of fruit and vegetables every day'. The Intention, Preferences and Self-efficacy items were scaled and scored as the Behavioural Skills items described above. Awareness (of 5-a-day) was measured by one question: 'How many servings of fruit and vegetables should a person at your age eat every day? This question had seven response alternatives ranging from 'none' $=0$ to 'more than 5 a day' $=6$.

\section{Parent questionnaire}

The parent questionnaire assessed items relating to the fruit and vegetable intake of the children. Child's Behavioural Skills, a behavioural factor, included four statements comparable to four of the pupil Behavioural Skills items, including: 'It happens that my child cuts up fruit or vegetables for him-/herself as a snack'. Parent's Own Fruit and Vegetable Intake, an environmental factor (modelling) for the pupils, was measured by the same four food frequency questions as for the pupils. Child's Accessibility was measured by five items, corresponding to the pupil items, such as: 'I (or my partner) sometimes cut up fruit or vegetables for my kid as a snack'. Child's Preferences were measured by two items: 'My kid likes fruit very much' and 'My kid likes vegetables very much'. The Child's Behavioural Skills, Child's Accessibility and the Child's Preferences items were also scaled and scored as the Behavioural Skills items.

All scales, including the number of items in the scale, range, number of participants, mean value, standard deviation and Cronbach's alpha value, are presented in Table 1 . In addition to these measures, demographic items and items regarding other health behaviours were included in this study, and were used in the attrition analysis for this paper.

\section{Statistics}

Missing values on any items were substituted by the mean value for the remaining group on the respective item. To achieve a score on a scale, more than $50 \%$ of the scale items had to be answered. A total of 268 children and 40 parents had one or more missing values substituted. While the missing substitution increased the number included in the analyses, it did not alter the findings presented in this paper. Multiple regression assumptions regarding normality, linearity and homoscedasticity were found to be acceptable, and therefore parametric statistics have been used. Multiple regression analyses were performed to determine the explained variance of the children's fruit and vegetable intake. Analyses were performed first with only the pupil scales as independent variables, then with only the parent scales as independent variables, and then with both pupil and parent scales combined. Regression coefficients $(B)$ and standardised regression coefficients $(\beta)$ are given for each independent variable. The unique amount of variance in intake explained by an independent variable is given by the square of the semi-partial correlation $(\text { sri2 })^{30,31}$. For each of the three analyses, the multiple correlation $(R)$, the variance explained $\left(R^{2}\right)$ and the adjusted variance explained (adj. $R^{2}$ ) are given. Pearson's correlation coefficients were computed to show the non-adjusted relationship between each variable and the intake, the relationship between the variables, and between the single items. Paired sample $t$-tests were used to assess differences in mean values in the parent-child comparisons, and two-sample $t$-tests were used to assess mean differences in the attrition analysis. Non-parametric tests were also applied, but the results did not differ from the parametric tests, and are therefore not reported.

Table 1 Description of the variables assessed, with the number of items, mean score, standard deviation (SD) and Cronbach's alpha

\begin{tabular}{|c|c|c|c|c|c|c|c|}
\hline SCT domain & Scale & No. of items & Range & $n$ & Mean & SD & Cronbach's alpha \\
\hline \multicolumn{8}{|l|}{ Pupils } \\
\hline \multirow{2}{*}{ Behavioural } & Intake (times/week) & 4 & $0 / 40$ & 1926 & 14.1 & 7.2 & NA \\
\hline & Behavioural Skills & 5 & $-10 / 10$ & 1948 & 1.1 & 4.1 & 0.62 \\
\hline \multirow[t]{2}{*}{ Environmental } & Accessibility & 5 & $-10 / 10$ & 1947 & 3.9 & 3.6 & 0.49 \\
\hline & Modelling & 4 & $-8 / 8$ & 1913 & 2.0 & 2.7 & 0.46 \\
\hline \multirow[t]{4}{*}{ Personal } & Intention (to eat 5-a-day) & 1 & $-2 / 2$ & 1936 & 0.2 & 1.3 & NA \\
\hline & Preferences & 4 & $-8 / 8$ & 1939 & 2.6 & 3.7 & 0.68 \\
\hline & Self-efficacy (to eat 5-a-day) & 3 & $-14 / 14$ & 1943 & 0.1 & 2.6 & 0.44 \\
\hline & Awareness (of 5-a-day) & 1 & $0 / 6$ & 1914 & 3.5 & 1.5 & NA \\
\hline \multicolumn{8}{|l|}{ Parents } \\
\hline Behavioural & Child's Behavioural Skills & 4 & $-8 / 8$ & 1631 & 0.5 & 3.7 & 0.62 \\
\hline \multirow{2}{*}{ Environmental } & Parent's Intake (times/week) & 4 & $0 / 40$ & 1632 & 14.2 & 5.8 & NA \\
\hline & Child's Accessibility & 5 & $-10 / 10$ & 1645 & 5.2 & 3.1 & 0.43 \\
\hline Personal & Child's Preferences & 2 & $-4 / 4$ & 1629 & 1.6 & 2.1 & 0.60 \\
\hline
\end{tabular}

SCT - Social Cognitive Theory; NA - not applicable. 
The chi-square test was used for dichotomous items in the attrition analysis.

\section{Results}

All independent variables were significantly correlated to the pupils' fruit and vegetable intake (Table 2). Behavioural Skills, Preferences and Accessibility were most strongly correlated to intake. As Behavioural Skills was highly correlated with Intake (0.57), and since it can be seen as a measure of aspects of fruit and vegetable eating behaviour, it (and its corresponding parent scale) has not been included as a determinant of intake in the multivariate analyses.

The six remaining pupil measures alone explained 31\% of the variance in the pupils' fruit and vegetable intake (Table 3, analysis A), with Intention being the only nonsignificant variable. Overall, $12 \%$ of the variance was explained by a unique contribution to the explanation, while the remaining 19\% was variance shared by two or more concepts. Accessibility and Preferences contributed most of the unique variance explained: $5 \%$ and $4 \%$, respectively. The three parent measures explained 12\% of the variance in the pupils' fruit and vegetable intake (Table 3, analysis B). Child's Accessibility was not significant. About $8 \%$ of the variance was explained by a unique contribution to the explanation. Child's Preferences and Parent's Intake contributed most of the unique variance explained $-6 \%$ and $2 \%$, respectively. Together, the nine pupil and parent scales explained 34\% of the variance in the pupils' fruit and vegetable intake (Table 3, analysis C). Intention and Child's Accessibility were the only variables that did not contribute significantly to the explanation. About $12 \%$ of the variance was explained by a unique contribution to the explanation. Accessibility and Preferences contributed most of the unique variance

Table 2 Pearson's correlation between all variables

\begin{tabular}{|c|c|c|c|c|c|c|c|c|c|c|c|c|c|}
\hline & & 1 & 2 & 3 & 4 & 5 & 6 & 7 & 8 & 9 & 10 & 11 & 12 \\
\hline \multicolumn{14}{|c|}{ Pupils } \\
\hline 1 & Intake (FFQ) & 1 & & & & & & & & & & & \\
\hline 2 & Behavioural Skills & 0.57 & 1 & & & & & & & & & & \\
\hline 3 & Accessibility & 0.44 & 0.50 & 1 & & & & & & & & & \\
\hline 4 & Modelling & 0.24 & 0.32 & 0.34 & 1 & & & & & & & & \\
\hline 5 & Intention (to eat 5-a-day) & 0.30 & 0.44 & 0.29 & 0.24 & 1 & & & & & & & \\
\hline 6 & Preferences & 0.45 & 0.63 & 0.40 & 0.27 & 0.51 & 1 & & & & & & \\
\hline 7 & Self-efficacy (to eat 5-a-day) & 0.34 & 0.46 & 0.31 & 0.22 & 0.48 & 0.49 & 1 & & & & & \\
\hline 8 & Awareness (of 5 a day) & 0.25 & 0.18 & 0.16 & 0.07 & 0.32 & 0.23 & 0.24 & 1 & & & & \\
\hline \multicolumn{14}{|c|}{ Parents } \\
\hline 9 & Child's Behavioural Skills & 0.29 & 0.35 & 0.15 & 0.08 & 0.16 & 0.31 & 0.20 & 0.10 & 1 & & & \\
\hline 10 & Parent's Intake (FFQ) & 0.23 & 0.13 & 0.20 & 0.17 & $0.05^{\star *}$ & 0.13 & 0.10 & $0.05^{*}$ & 0.30 & 1 & & \\
\hline 11 & Child's Accessibility & 0.20 & 0.17 & 0.29 & 0.12 & $0.06^{\star}$ & 0.09 & 0.09 & $0.06^{*}$ & 0.39 & 0.49 & 1 & \\
\hline 12 & Child's Preferences & 0.29 & 0.33 & 0.12 & 0.09 & 0.15 & 0.33 & 0.19 & 0.07 & 0.66 & 0.20 & 0.25 & 1 \\
\hline
\end{tabular}

FFQ - food frequency questions.

Most correlations are significant at the 0.01 level (two-tailed)

${ }^{*}$ Correlation significant at the 0.05 level (two-tailed).

${ }^{\star *}$ Correlation not significant at the 0.05 level (two-tailed)

Table 3 Explaining the variance in children's fruit and vegetable intake using pupil and parent variables (multiple regression)

\begin{tabular}{|c|c|c|c|c|c|c|c|c|c|c|c|c|}
\hline & \multicolumn{4}{|c|}{ Analysis $\mathrm{A}(n=1846)$} & \multicolumn{4}{|c|}{ Analysis $\mathrm{B}(n=1596)$} & \multicolumn{4}{|c|}{ Analysis C $(n=1534)$} \\
\hline & $B$ & $\beta$ & $P$-value & sri2 & $B$ & $\beta$ & $P$-value & sri2 & $B$ & $\beta$ & $P$-value & sri2 \\
\hline \multicolumn{13}{|l|}{ Pupils } \\
\hline Accessibility & 0.52 & 0.27 & $<0.01$ & 0.054 & & & & & 0.50 & 0.26 & $<0.01$ & 0.047 \\
\hline Modelling & 0.12 & 0.05 & 0.03 & 0.002 & & & & & 0.13 & 0.05 & 0.03 & 0.002 \\
\hline Intention (to eat 5-a-day) & -0.02 & 0.00 & 0.90 & 0.000 & & & & & -0.01 & 0.00 & 0.93 & 0.000 \\
\hline Preferences & 0.51 & 0.26 & $<0.01$ & 0.042 & & & & & 0.40 & 0.21 & $<0.01$ & 0.024 \\
\hline Self-efficacy (to eat 5-a-day) & 0.26 & 0.10 & $<0.01$ & 0.006 & & & & & 0.24 & 0.09 & $<0.01$ & 0.005 \\
\hline Awareness (of 5-a-day) & 0.58 & 0.12 & $<0.01$ & 0.013 & & & & & 0.59 & 0.12 & $<0.01$ & 0.014 \\
\hline \multicolumn{13}{|l|}{ Parents } \\
\hline Parent's Intake (FFQ) & & & & & 0.18 & 0.15 & $<0.01$ & 0.017 & 0.12 & 0.10 & $<0.01$ & 0.007 \\
\hline Child's Accessibility & & & & & 0.13 & 0.06 & 0.04 & 0.002 & -0.02 & -0.01 & 0.66 & 0.000 \\
\hline Child's Preferences & & & & & 0.82 & 0.25 & $<0.01$ & 0.057 & 0.48 & 0.14 & $<0.01$ & 0.017 \\
\hline$R$ & 0.558 & & & & 0.342 & & & & 0.587 & & & \\
\hline$R^{2}$ & 0.311 & & & & 0.117 & & & & 0.345 & & & \\
\hline Adj. $R^{2}$ & 0.309 & & & & 0.115 & & & & 0.341 & & & \\
\hline Sum sri2 & & & & 0.118 & & & & 0.077 & & & & 0.116 \\
\hline
\end{tabular}

FFQ - food frequency questions.

Analysis A - only pupils' scales are included as independent variables in the model; Analysis B - only parents' scales are included as independent variables in the model; Analysis C - pupils' and parents' scales are included as independent variables in the model. 
explained - 5\% and 2\%, respectively. Analysis A was also done on a reduced sample including only pupils whose parents had participated. The results did not differ from those reported in Table 3. The results are presented by gender and grade combined, since no significant gender or grade interactions were seen for any of the factors.

Based on the applied frequency measure, children and their parents reported eating fruits and vegetables equally as often (14.1 vs. 14.2 times/week). The correlation between children's and parents' fruit and vegetable intake was 0.23 (Table 2 ), the correlations for fruits and vegetables were $0.18(P<0.001)$ and $0.22(P<0.001)$, respectively.

The parent-child correlations on the parallel scales, Behavioural Skills, Accessibility and Preferences, were moderate $(0.30-0.35)$ (Table 2$)$. The parents perceived the accessibility for their children to be better than that reported by the children. The children, on the other hand, reported their skills to be better than what was perceived by their parents (Table 4). Correlations between parents' and children's responses on single parallel accessibility and skills items ranged from 0.13 to 0.40 , all statistically significant (Table 4).

Compared to children with participating parents ( $n=1647)$, the children without participating parents $(n=303)$ ate less fruit and vegetables. Furthermore, they had significantly lower scores on the scales assessing skills, accessibility and preferences. Pupils with nonparticipating parents also were more likely to be boys, in 7th grade, living with a single parent, and to have experimented with cigarette smoking (Table 5).

\section{Discussion}

This study shows that a large portion of 6th and 7th graders' fruit and vegetable intake can be explained by environmental and personal factors, as postulated by SCT.

Preferences and accessibility seem to be the strongest correlates to the children's fruit and vegetable intake. This is consistent with findings from previous studies. Woodward et al. ${ }^{14}$ showed that 12 - to 15 -year-old pupils' liking of a particular fruit or vegetable (apple, orange juice, potato and tomato) was associated with their usage of that type, and was also more strongly associated with intake than perceived healthfulness, perceived friends' usage and perceived parents' usage (only orange juice and potato). Domel et al. reported correlations between preferences and consumption among 4th- and 5th-grade pupils by asking participants how much they liked 10 frequently consumed fruits and vegetables ${ }^{12,13}$. Correlation between fruit preferences and fruit consumption were reported to be 0.25 and 0.20 , and between vegetable preferences and vegetable consumption correlations were 0.28 and 0.27 in two separate studies ${ }^{12,13}$. Resnicow et al. ${ }^{10}$ reported a correlation of 0.29 between fruit and vegetable preferences and fruit and vegetable intake using the same preference measures as Domel's, but combining fruit and

Table 4 Parent-child comparisons on parallel items of accessibility and behavioural skills

\begin{tabular}{|c|c|c|c|c|c|c|c|}
\hline & \multirow[b]{2}{*}{$n$ (pairs) } & \multicolumn{2}{|c|}{ Pupils } & \multicolumn{2}{|c|}{ Parents } & \multirow[b]{2}{*}{$P$-value* } & \multirow{2}{*}{$\begin{array}{l}\text { Pearson's } \\
\text { correlation** }\end{array}$} \\
\hline & & Mean & SD & Mean & SD & & \\
\hline \multicolumn{8}{|l|}{ Accessibility items } \\
\hline $\begin{array}{l}\text { At home we usually always have fruit and } \\
\text { vegetables in the refrigerator }\end{array}$ & 1638 & 1.2 & 1.2 & 1.5 & 0.9 & $<0.01$ & 0.19 \\
\hline $\begin{array}{l}\text { At home I am (my child is) allowed } \\
\text { to eat fruit and vegetables } \\
\text { whenever I (he/she) want(s) }\end{array}$ & 1634 & 1.6 & 0.8 & 1.7 & 0.7 & $<0.01$ & 0.13 \\
\hline $\begin{array}{l}\text { Mother or father do (I or my partner) } \\
\text { sometimes cut up fruit or vegetables } \\
\text { for me (my child) as a snack }\end{array}$ & 1627 & -0.2 & 1.5 & -0.1 & 1.5 & $<0.01$ & 0.23 \\
\hline $\begin{array}{l}\text { At home we usually have vegetables } \\
\text { at dinner every day }\end{array}$ & 1622 & 0.3 & 1.4 & 1.0 & 1.2 & $<0.01$ & 0.22 \\
\hline $\begin{array}{l}\text { At home we usually have fruit available } \\
\text { in a (fruit-) bowl }\end{array}$ & 1642 & 1.2 & 1.3 & 1.1 & 1.2 & 0.11 & 0.40 \\
\hline Sum & 1572 & 4.0 & 3.7 & 5.2 & 3.2 & $<0.01$ & 0.30 \\
\hline \multicolumn{8}{|l|}{ Behavioural Skills items } \\
\hline $\begin{array}{l}\text { It happens that I cut (my child cuts) up fruit or } \\
\text { vegetables for myself (him-/herself) as a snack }\end{array}$ & 1631 & 0.2 & 1.4 & -0.3 & 1.5 & $<0.01$ & 0.21 \\
\hline $\begin{array}{l}\text { It happens often that I find (my child finds) } \\
\text { myself (him-/herself) fruit and vegetables } \\
\text { at home between meals }\end{array}$ & 1625 & 1.0 & 1.2 & 1.0 & 1.2 & 0.03 & 0.31 \\
\hline $\begin{array}{l}\text { I (my child) always finish (eats up) } \\
\text { my (his/her) vegetables for dinner }\end{array}$ & 1630 & 0.7 & 1.4 & 0.4 & 1.4 & $<0.01$ & 0.33 \\
\hline $\begin{array}{l}\text { I eat (my child eats) fruit or vegetables } \\
\text { at every meal }\end{array}$ & 1613 & -0.7 & 1.1 & -0.6 & 1.2 & 0.18 & 0.18 \\
\hline Sum & 1569 & 1.3 & 3.3 & 0.5 & 3.7 & $<0.01$ & 0.34 \\
\hline
\end{tabular}

SD - standard deviation.

${ }^{*}$ Paired samples $t$-test.

${ }^{\star *}$ All correlations are significant at the 0.01 level. 
Table 5 Comparison of pupils with parents participating and pupils without parents participating

\begin{tabular}{|c|c|c|c|}
\hline & $\begin{array}{l}\text { Pupil and parent } \\
\text { data }(n=1647)\end{array}$ & $\begin{array}{c}\text { Pupil data } \\
\text { only }(n=303)\end{array}$ & $P$-value* \\
\hline Sex (\% female) & 51 & 42 & $<0.01$ \\
\hline Grade (\% 6th grade) & 54 & 44 & $<0.01$ \\
\hline Live with single parent (\%) & 16 & 29 & $<0.01$ \\
\hline Tried smoking a cigarette (\%) & 13 & 23 & $<0.01$ \\
\hline Tried alcohol (\%) & 45 & 51 & 0.05 \\
\hline Trying to lose weight (\%) & 8 & 11 & 0.03 \\
\hline TV/PC usage $\left(\right.$ day $\left.^{-1}\right)$ & 2.0 & 2.3 & 0.03 \\
\hline Physical activity (times/week) & 3.3 & 3.3 & 0.76 \\
\hline FV intake (times/week) & 14.3 & 13.2 & 0.02 \\
\hline Behavioural Skills & 1.2 & 0.5 & 0.01 \\
\hline Accessibility & 4.0 & 3.4 & 0.01 \\
\hline Modelling & 2.0 & 1.8 & 0.18 \\
\hline Intention (to eat 5-a-day) & 0.3 & 0.1 & 0.14 \\
\hline Preferences & 2.8 & 2.1 & $<0.01$ \\
\hline Self-efficacy (to eat 5-a-day) & 0.1 & 0.1 & 0.83 \\
\hline Awareness (of 5-a-day) & 3.5 & 3.4 & 0.27 \\
\hline
\end{tabular}

vegetable preference into one scale. Reynolds et $a l^{6}{ }^{6}$, also using the preferences measures developed by Domel and colleagues, found that preferences, as a part of a motivation latent construct together with perceived selfefficacy and outcome expectancies, was a correlate to 4thgrade children's fruit and vegetable intake.

Few studies have investigated the relationship between availability/accessibility of fruit and vegetables at home and children's intake of fruit and vegetables. Kratt et $a l^{21}$ showed that children (4th graders) from homes with high levels of fruit and vegetables available/accessible had a higher consumption of fruit and vegetables than children from homes with medium and low levels of fruit and vegetables available/accessible. Significant differences were found between all three groups. Hearn et al. ${ }^{20}$ have shown that home availability and accessibility of fruits and vegetables is positively related to 3rd graders' fruit and vegetable consumption. The availability measures used in these two studies were similar; parents were asked whether a number of different fruit and vegetables had been available and accessible at home the previous week. Reynolds, using the availability measures developed by Hearn and colleagues, reported that availability had a direct effect on consumption in two out of four subsamples, and an indirect effect through motivation (same latent construct as described above) in the other two. A study asking 4th-6th graders the same kinds of questions found significant correlations between fruit and vegetable consumption and both fruit availability $(r=0.17)$ and vegetable availability $(r=0.28)^{17}$.

The relationships between preferences and intake and availability/accessibility and intake appear higher in our study than reported elsewhere. This could be because we used somewhat different measures for preferences and availability, as well as a different method for assessing intake. Our measure of preferences was a more general measure, asking, on a 5-point scale, to what degree the participants agreed with statements about how well they liked fruit and/or vegetables in general. Our accessibility items were more situational than other availability/accessibility measures, assessing whether fruit or vegetables in general were available or accessible, and usual/habitual accessibility was measured (rather than availability/accessibility for the past week). Fruit and vegetable intake was also measured as the usual/habitual intake (over the last three months) with food frequency questions. Most other studies measured actual intake with a single 24-hour recall $^{6,21}$ or with $3-7$ days of recording ${ }^{10,12,13,17,20}$; only one other study measured intake by food frequency questions $^{14}$.

All other variables, besides preferences and accessibility, were correlated to the children's intake, but in the multiple regression analysis, because of their correlation with other constructs, their contribution to explaining the variance diminished. Ideally, the inter-correlation between independent variables should be low, while each variable should be strongly associated with the behaviour $^{31}$. Large inter-correlation between the independent variables makes it difficult to assess which variables predict behaviour and by how much ${ }^{31}$. In regression analysis A (Table 3, analysis A), 31\% of the variance in the intake was explained. Only $12 \%$ of the variance in intake was explained by unique contribution of the significant independent variables, almost exclusively by preferences and accessibility. The remaining $19 \%$ of the variance was explained by the shared variance of two or more independent variables. This is a common problem, as variables related to the same behaviour naturally correlate with one another. This 'shared variance' problem creates 
challenges to developing more precise measures of the various constructs.

The correlation observed between the children's and their parents' fruit and vegetable intake indicates that the parents' intake is a potential determinant for the children's intake. Parents' intake also contributed to some unique variation in the explanation of the children's intake. The parent-child correlations for fruit and vegetables separately were of the same magnitude as for fruit and vegetables combined, indicating that there is an association between children's and their parents' intake for both fruit and vegetables, not for fruit only, as previously reported $^{18}$.

The parent-child correlations of the three parallel scales (Behavioural Skills, Accessibility and Preferences) appear rather low. Since these scales should measure the same phenomenon, but still are only moderately correlated, it is clear that one cannot be substituted for another. Parents and their children seem to perceive the children's accessibility and skills differently. Overall, the participating parents perceived their children's accessibility to be much higher than did the children themselves. At the same time, the children perceived their own skills to be higher than did their parents. The observed discrepancy in perceived accessibility is of major concern since accessibility, as shown, is a strong correlate for the children's intake of fruits and vegetables. If the parents perceive the accessibility to be good enough, as indicated in this study by high mean item scores, such perceptions could be barriers to increasing intake of fruits and vegetables among children.

Children whose parents did not participate differed from children with participating parents with regard to demographic variables, health-related behaviours and fruit and vegetable intake measures. However, when conducting the regression analysis (presented in Table 3, analysis A) among only those children whose parents participated, the results did not change. Thus, we do not believe that the attrition observed in this study reduces the generalisability of the findings.

\section{Conclusions and implications}

A significant amount of the variance in 6th and 7th graders' fruit and vegetable intake was explained by the factors included in this study. Preferences and accessibility to fruits and vegetables were most strongly correlated to fruit and vegetable intake among children. Both the children's fruit and their vegetable intake correlated with their parents' respective intake. Children and their parents perceived the children's accessibility to and skills related to fruit and vegetables differently.

Accessibility to fruit and vegetables appears to be an important factor for children's fruit and vegetable intake. Parents tended to perceive their children's accessibility to fruit and vegetables to be better than what the children themselves perceived. Since parents are in control of access to fruit and vegetables at home and their intake is correlated to the children's intake, nutrition interventions aimed at parents are clearly needed.

An important next research step will be to investigate whether the identified correlates predict future fruit and vegetable intake in both prospective cohort studies as well as longitudinal experimental intervention studies. Also important is studying whether these correlates mediate changes in intake. Such mediation studies are clearly lacking $^{5,32}$.

\section{Acknowledgements}

This study was funded by the Norwegian Research Council. The authors wish to thank research assistants Mona Bjelland, Marthe Bottolfs, Nina Kolbjørnsen, Kaja Lund-Iversen, Cathrine Muryn and Jorunn Sofie Randby for their participation in data collection and processing.

\section{References}

1 World Cancer Research Fund (WCRF)/American Institute for Cancer Research (AICR). Food, Nutrition and the Prevention of Cancer. Washington, DC: WCRF/AICR, 1997.

2 National Nutrition Council. Recommendations for Increased Intake of Fruits and Vegetables. Oslo: National Nutrition Council, 1996 [in Norwegian].

3 Johansson L, Andersen LF. Who eats 5 a day? Intake of fruits and vegetables among Norwegians in relation to gender and lifestyle. Journal of the American Dietetic Association 1998; 98: 689-91.

$4 \varnothing$ verby NC, Andersen LF. Ungkost-2000: Nationwide Dietary Survey among 4 th and 8th graders in Norway. Oslo: National Nutrition Council, 2002 [in Norwegian].

5 Baranowski T, Lin LS, Wetter DW, Resnicow K, Hearn MD. Theory as mediating variables: why aren't community interventions working as desired? Annals of Epidemiology 1997; (Suppl.7): 89-95.

6 Reynolds KD, Hinton AW, Shewchuk RM, Hickey CA. Social cognitive model of fruit and vegetable consumption in elementary school children. Journal of Nutrition Education 1999; 31: 23-30.

7 Osler M, Hansen ET. Dietary knowledge and behaviour among schoolchildren in Copenhagen, Denmark. Scandinavian Journal of Social Medicine 1993; 21: 135-40.

8 Domel SB, Baranowski T, Davis HC, Thompson WO, Leonard SB, Baranowski J. A measure of outcome expectations for fruit and vegetable consumption among 4 th and 5 th grade children - reliability and validity. Health Education Research 1995; 10: 65-72.

9 Baranowski T, Cullen KW, Baranowski J. Psychosocial correlates of dietary intake: advancing dietary intervention. Annual Review of Nutrition 1999; 19: 17-40.

10 Resnicow K, Hearn MD, Smith M, Baranowski T, Lin LS, Baranowski J. Social-cognitive predictors of fruit and vegetable intake in children. Health Psychology 1997; 16: 272-6.

11 Birch LL, Fisher JO. Development of eating behaviours among children and adolescents. Pediatrics 1998; 101: 539-49.

12 Domel SB, Thompson WO, Davis HC, Baranowski T, Leonard SB, Baranowski J. Psychosocial predictors of fruit 
and vegetable consumption among elementary school children. Health Education Research 1996; 11: 299-308.

13 Domel SB, Baranowski T, Davis H, Leonard SB, Riley P, Baranowski J. Measuring fruit and vegetable preferences among 4th- and 5th-grade students. Preventive Medicine 1993; 22: 866-79.

14 Woodward DR, Boon JA, Cumming FJ, Ball PJ, Williams HM, Hornsby H. Adolescents' reported usage of selected foods in relation to their perceptions and social norms for those foods. Appetite 1996; 27: 109-17.

15 Heatey KR, Thombs DL. Fruit-vegetable consumption selfefficacy in youth. American Journal of Health Behavior 1997; 21: 172-7.

16 Lien N, Lytle LA, Komro KA. Applying theory of planned behaviour to fruit and vegetable consumption of young adolescents. American Journal of Health Promotion 2002 16: $189-97$.

17 Cullen KW, Baranowski T, Rittenberry L, Cosart C, Hebert D, deMoor C. Child-reported family and peer influences on fruit, juice and vegetable consumption: reliability and validity of measures. Health Education Research 2001; 16 $187-200$.

18 Gibson EL, Wardle J, Watts CJ. Fruit and vegetable consumption, nutritional knowledge and beliefs in mothers and children. Appetite 1998; 31: 205-28.

19 French SA, Story M, Jeffery RW. Environmental influences on eating and physical activity. Annual Review of Public Health 2001; 22: 309-35.

20 Hearn MD, Baranowski T, Baranowski J, Doyle C, Smith M, Lin LS. Environmental influences on dietary behaviour among children: availability and accessibility of fruits and vegetables enable consumption. Journal of Health Education 1998; 29: 26-32

21 Kratt P, Reynolds K, Shewchuk R. The role of availability as a moderator of family fruit and vegetable consumption. Health Education \& Behavior 2000; 27: 471-82.

22 Story M, Neumark-Sztainer D, French S. Individual and environmental influences on adolescent eating behaviours. Journal of the American Dietetic Associatio 2002; (Suppl. 102): 40-51.

23 Roos EB, Hirvonen T, Mikkila V, Karvonen S, Rimpela M. Household educational level as a determinant of consumption of raw vegetables among male and female adolescents. Preventive Medicine 2001; 33: 282-91.

24 Lien N, Jacobs DR, Klepp K-I. Exploring predictors of eating behaviour among adolescents by gender and socioeconomic status. Public Health Nutrition 2002; 5: 671-81.

25 Baranowski T, Perry CL, Parcel GS. How individuals, environments, and health behaviour interacts. In: Glanz K, Lewis FM, Rimer BK, eds. Health Behaviour and Health Education: Theory Research, and Practice, 2nd ed. San Francisco, CA: Jossey-Bass Publishers, 1997; 153-78.

26 Bandura A. Social Foundations of Thought and Action: A Social Cognitive Theory. Englewood Cliffs, NJ: Prentice-Hall, 1986.

27 Wardle J. Parental influences on children's diet. Proceedings of the Nutrition Society 1995; 54: 747-58.

28 Bere E, Klepp K-I. Reliability of parental and self-reported determinants of fruit and vegetable intake among 6th graders. Public Health Nutrition 2004; 7: 353-6.

29 Andersen LF, Bere E, Kolbjørnsen N, Klepp K-I. Validity and reproducibility of self-reported intake of fruit and vegetables among 6th graders. European Journal of Clinical Nutrition 2004; 58: 771-7.

30 Hankins M, French D, Horne R. Statistical guidelines for studies of the theory of reasoned action and the theory of planned behaviour. Psychology \& Health 2000; 15: 151-61.

31 Tabachnick BG, Fidell LS. Multiple regression. In: Tabachnick BG, Fiedell LS, eds. Using Multivariate Statistics, 4th ed. Needham Heights, MA: Allyn \& Bacon, 2001; 111-76.

32 Reynolds KD, Yaroch AL, Franklin FA, Maloy J. Testing mediating variables in a school-based nutrition intervention program. Health Psychology 2002; 21: 51-60. 